\title{
An Aircraft-Based Study of Strong Gap Flows in Nares Strait, Greenland $\mathscr{O}$
}

\author{
GÜNTHER HEINEMANN \\ Department of Environmental Meteorology, University of Trier, Trier, Germany
}

(Manuscript received 16 May 2018, in final form 29 August 2018)

\begin{abstract}
Gap flows and the stable boundary layer were studied in northwest Greenland during the aircraft-based Investigation of Katabatic Winds and Polynyas during Summer (IKAPOS) experiment in June 2010. The measurements were performed using the research aircraft POLAR 5 of Alfred Wegener Institute (AWI; Bremerhaven). Besides navigational and basic meteorological instrumentation, the aircraft was equipped with radiation and surface temperature sensors and a turbulence measurement system. In the area of Smith Sound at the southern end of the Nares Strait, a stable, but fully turbulent, boundary layer with strong winds of up to $22 \mathrm{~m} \mathrm{~s}^{-1}$ was found during conditions of synoptically induced northerly winds through the Nares Strait. Strong surface inversions were present in the lowest $100-200 \mathrm{~m}$. As a consequence of channeling effects, a well-pronounced low-level jet system was documented for each of four flights. The wind maximum is located at 20-50-km distance from the exit of Smith Sound. The 3D boundary layer structure past this gap is studied in detail. The channeling process is consistent with gap flow theory. The flow through the gap and over the surrounding mountains leads to the lowering of isotropic surfaces and the acceleration of the flow. The orographically channeled flow through Smith Sound plays a key role for the formation of the North Water polynya being the largest ice-producing polynya in the Arctic.
\end{abstract}

\section{Introduction}

The area of the Nares Strait in northwest Greenland (Fig. 1; Fig. S2 in the online supplemental material) is one of the key areas of the Arctic due to the presence of the North Water polynya (NOW), which forms at the north end of Baffin Bay. The NOW is mainly wind driven (Barber et al. 2001; Yao and Tang 2003), and it is biologically very productive and the most ice-producing polynya of the Arctic (Iwamoto et al. 2014; Preußer et al. 2016). The NOW is primarily a latent heat polynya during winter, since it forms in an area where the ocean temperature is at the freezing point, and the sea ice is transported away by winds or ocean currents directly after its formation. Moore and Våge (2018) find for winter 2016 extremes of more than $1000 \mathrm{~W} \mathrm{~m}^{-2}$ for the total turbulent atmospheric heat flux over the NOW. The Smith Sound and a corresponding ice bridge are important for the formation of the NOW. The ice bridge

Supplemental information related to this paper is available at the Journals Online website: https://doi.org/10.1175/MWR-D-18-0178.s1.

\footnotetext{
Corresponding author: Günther Heinemann, heinemann@unitrier.de
}

forms at Smith Sound when northerly winds advect sea ice southward through the Kane Basin (Fig. 1). The NOW area is covered by thin ice during winter, and its mean area during winter is about $30000 \mathrm{~km}^{2}$ for the years 2002-11 (Preußer et al. 2015). The polynya starts to expand in April and reaches a maximum area in July (Barber et al. 2001).

While the polynya has strong heat loss by net radiation and atmospheric turbulent heat fluxes and is associated with a convective boundary layer during winter and spring, the polynya gains energy by shortwave radiation during summer. With the sea surface being still near the freezing point, a stable boundary layer (SBL) develops over the polynya, if warm air is advected. In this case, the sensible heat flux represents an additional energy input regardless of cloud conditions.

The topography of Nares Strait and Smith Sound is not only important for the ice bridge associated with the NOW formation, but it can lead also to channeling of the flow in the ABL. Nares Strait has a total length of $450 \mathrm{~km}$ (Fig. S2), and the main regions of channeling are the Kennedy Channel north of the Kane Basin and Smith Sound south of the Kane Basin (Fig. 1). The increased wind speed then has a feedback with the sea ice/ ocean interface, leading to increased ice advection and 


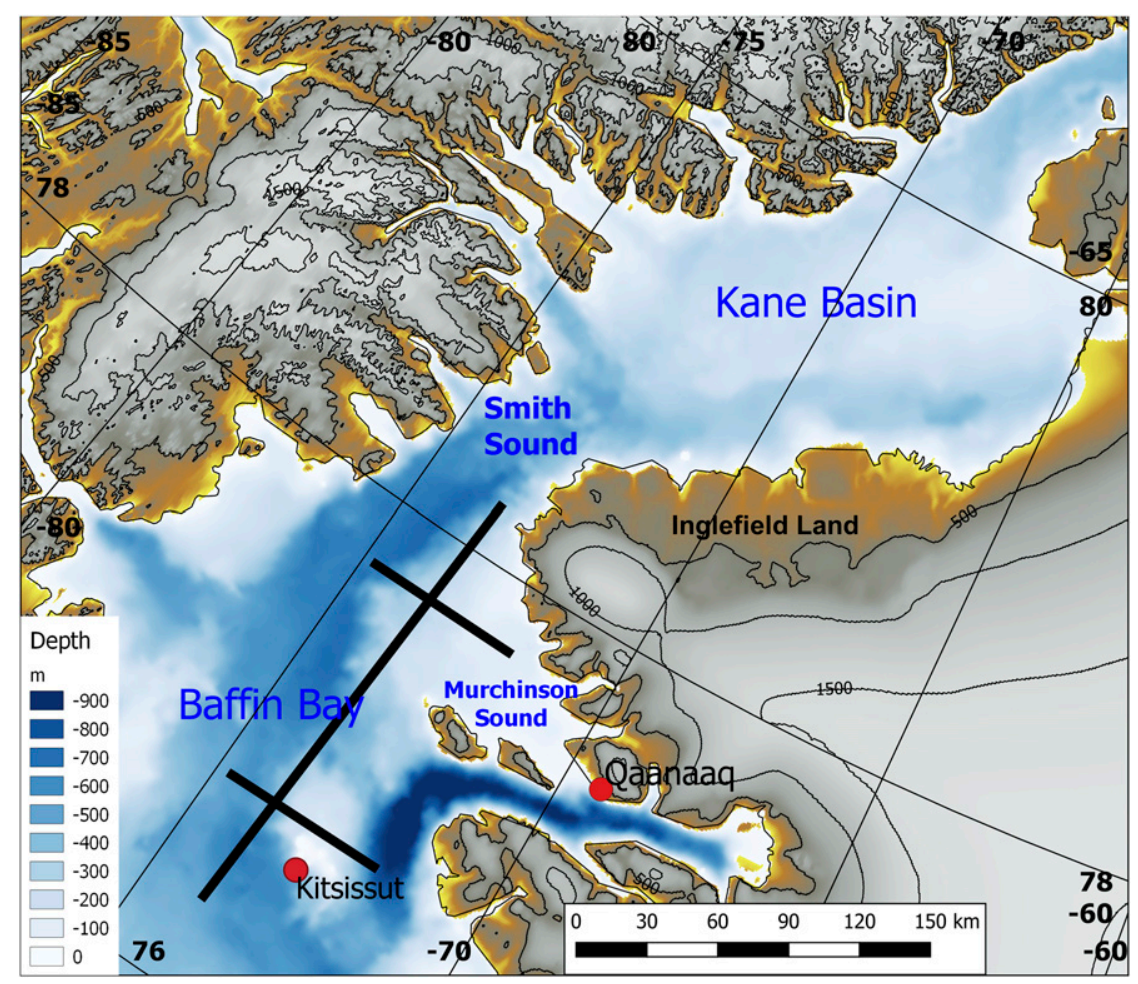

FIG. 1. Experimental area with topography (isolines) and ocean depth (blue shading) with a plot of the flight pattern on 15 Jun 2010 as thick lines [topography data from USGS/NGA (2010)].

surface exchange processes. Melling (2011) reports winds of more than $25 \mathrm{~m} \mathrm{~s}^{-1}$ in April 2005 measured at an ice camp in the Kennedy Channel. In situ measurements by Ito (1982) in the Kane Basin show that northerly winds are dominant and are accelerated when passing Smith Sound. A pronounced wind maximum due to channeling is found by modeling studies (Samelson and Barbour 2008), indicating that pressure gradients resulting from the topography of the Nares Strait cause a low-level jet. Moore and Våge (2018) show that a pressure difference of $7-8 \mathrm{hPa}$ is present between the Kane Basin and $\sim 100 \mathrm{~km}$ south of Smith Sound in the highresolution ECMWF analysis for winter 2016. Gutjahr and Heinemann (2018) perform a model-based analysis of wind extremes in the Arctic for 37 winters and find the Nares Strait as one of the areas with highest extremes of about $23 \mathrm{~m} \mathrm{~s}^{-1}$ for the $95 \%$ percentile and about $31 \mathrm{~m} \mathrm{~s}^{-1}$ for the 10-yr return level. Since the formation of the NOW is mainly wind driven (Yao and Tang 2003), these channeling effects are of large importance for the NOW dynamics and the ocean circulation within the Nares Strait (Münchow et al. 2006). Furthermore, Steffen (1985) points out that the channeled winds in Smith Sound also cause coastal upwelling of warm water along the Greenland coast, which is estimated to keep $10 \%$ of the NOW ice free.
The present paper presents a study of the ABL structure in the region of the NOW during summer using an instrumented research aircraft. A fully turbulent stable boundary layer and a well-pronounced low-level jet (LLJ) system are documented. Section 2 describes the experiment setup, the data, and the methods. Section 3 gives an overview of the four flights, and section 4 investigates the channeling process at the topographic gap between Greenland and Canada represented by the Smith Sound. Finally, a summary and conclusion section is given.

\section{Data and experiment setup}

The aircraft-based Investigation of Katabatic Winds and Polynyas during Summer (IKAPOS) experiment was performed in June 2010. The goal of this experiment was the investigation of the boundary layer over the Greenland Ice Sheet and the NOW. A detailed description of the experimental setup, the flight missions, the calibration of aircraft sensors, and first results is given by the field phase report (Heinemann et al. 2011). In the present paper, only results for the NOW are presented.

\section{a. Experimental area}

The experimental area is located in northwestern Greenland (Fig. 1). Qaanaaq was chosen as the base of 
TABLE 1. POLAR 5 instrumentation.

\begin{tabular}{lcl}
\hline \multicolumn{1}{c}{ Quantity } & Sampling $(\mathrm{Hz})$ & \multicolumn{1}{c}{ Sensor, manufacturer } \\
\hline Position & 1 & 2 GPS, Trimble RTS \\
Position, orientation & 50 & INS, Honeywell Laserref V \\
Height & 100 & Radar altimeter, Honeywell \\
& 20 & Laser altimeter PS100(E), Ibeo \\
& 200 & Laser altimeter LD90-3, Riegl \\
Air pressure, air speed & 20 & Pitot tube and static pressure sensor, Rosemount \\
Surface temperature & 20 & KT15.85D, Heitronics \\
Downward and upward radiation & 20 & 2 Pyranometer PSP, Eppley \\
& & 2 Pyrgeometer PIR, Eppley \\
Air temperature & 20 & Pt100 open wire deiced, Rosemount \\
Air humidity & 20 & Humicap HMT333, Vaisala \\
& 1 & Dewpoint mirror CR2, Buck research Instruments \\
\hline
\end{tabular}

IKAPOS, because it provides relatively good logistic conditions. Qaanaaq is the main village of northern Greenland (approximately 650 inhabitants), and Qaanaaq Airport is the only civil airport north of Upernavik (Fig. S1). The U.S. Air Force base Thule Airbase (approximately $110 \mathrm{~km}$ south of Qaanaaq) is not accessible for non-U.S. research aircrafts. The Smith Sound lies close to Qaanaaq and separates northwest Greenland and Ellesmere Island (Canada). Sea ice export rates through the Nares Strait from the Arctic Ocean are significant (see, e.g., Barber et al. 2001; Kwok 2005; Samelson et al. 2006; Kwok et al. 2010). In the south, Smith Sound (40-50 km wide) links Nares Strait with Baffin Bay, the NOW region. The experimental phase was from 9 (arrival of the aircraft at Qaanaaq) to 27 June (departure from Qaanaaq).

\section{b. Aircraft and instrumentation}

The aircraft used was the research aircraft POLAR 5 (Wesche et al. 2016) owned by the Alfred Wegener Institute (AWI). It is a rebuilt DC-3 (Douglas Company), converted by Basler Turbo Conversions (known as Basler BT-67). POLAR 5 has a length of $21 \mathrm{~m}$, a wing span of $29 \mathrm{~m}$, and a maximum range (without cargo) of $1900 \mathrm{~km}$ (Fig. S3). The maximum scientific cargo is $2500 \mathrm{~kg}$. Measurements were performed at typical speed of $70 \mathrm{~m} \mathrm{~s}^{-1}$.
POLAR 5 was instrumented with turbulence sensors, basic meteorological equipment, radiation and surface temperature sensors, two laser altimeters, and video and digital cameras (Tables 1 and 2). The turbulence measurement system is installed on a nose boom (Fig. S3). High-resolution measurements at a sampling rate of $100 \mathrm{~Hz}$ allow for the calculation of turbulent fluxes. The radiation sensor processor of the data acquisition system failed on 17 and 18 June, so radiation fluxes and surface temperature are not available for some flights (see Table 3).

Between 12 and 23 June, a total of four NOW research flights were performed (Table 3, Fig. 1). A comprehensive in-flight calibration has been carried out. This is necessary, since several instrument properties are either undocumented or arise from interactions between sensors and the whole measurement platform (e.g., sensor time constants, aerodynamic recovery factors, and time lags in turbulence data processing). Another reason is that calibration coefficients (possibly) vary from installation to installation, depend on the actual electrical or mechanical configuration of (optional) sensors, or change with evolving software development of the data acquisition (e.g., radiation sensor misalignment, local angel-of-attack correction). In-flight calibration of aircraft sensors was performed during a special calibration flight on 12 June 2010. The calibration procedure is described by Drüe and Heinemann (2013).

TABLE 2. Turbulence measurement system instrumentation.

\begin{tabular}{lcl}
\hline \hline \multicolumn{1}{c}{ Quantity } & Sampling $(\mathrm{Hz})$ & \multicolumn{1}{c}{ Sensor, manufacturer } \\
\hline 3D wind & 100 & 5-hole probe, Rosemount \\
Air temperature & 100 & Pt100 open wire deiced, Rosemount \\
& 100 & Pt100 open wire, Rosemount \\
Air humidity & 100 & Lyman- $\alpha$, Buck Research Instruments \\
& 100 & Humicap HMT333, Vaisala \\
& 100 & Dewpoint mirror 1011B, General Eastern \\
\hline
\end{tabular}


TABLE 3. Flight missions for the NOW program during June 2010.

\begin{tabular}{cll}
\hline \hline Date, flight time & \multicolumn{1}{c}{ Flight, topic } & \multicolumn{1}{c}{ Location } \\
\hline 1350-1705 UTC 12 Jun & CAL, calibration & Over Smith Sound at 3000 m \\
1245-1825 UTC 15 Jun & NW1, polynya & Smith Sound, northern Baffin Bay \\
1355-1850 UTC 18 Jun & NW2, polynya & Smith Sound, northern Baffin Bay \\
1215-1720 UTC 22 Jun & NW3, polynya & Smith Sound, northern Baffin Bay \\
1315-1835 UTC 23 Jun & NW4, polynya & Northern Baffin Bay, Smith Sound, \\
& & southern Kane Basin \\
\hline
\end{tabular}

\section{c. Aircraft data analysis}

Two basic flight patterns were flown: 1) vertical profiles (slantwise ascents and descents) for a fast measurement of the ABL structure and 2) flight legs at different levels above the ground for the measurement of turbulent fluxes and horizontal profiles. Although the turbulent fluxes were calculated by the eddy covariance method, as in Heinemann (2002), results are not shown here, since in the present study the focus lies on the mean boundary layer structure. For this purpose, a more convenient $1-\mathrm{Hz}$ subset was extracted from the $100-\mathrm{Hz}$ dataset. For the vertical profiles, turbulent fluctuations are filtered out using a low-pass filter of $0.05 \mathrm{~Hz}$. From the filtered vertical profiles of the mean quantities, vertical gradients such as the potential temperature gradient and the gradients of wind components are computed, which are needed, for example, for the analysis of the Richardson number.

The determination of the boundary layer height from vertical profiles for the SBL is done by using a temperature gradient criterion similar to previous studies (Heinemann 1999, 2002; Heinemann and Klein 2002). The procedure is illustrated in Fig. S4. Three typical cases occur for the SBL. Case 1 represents a surfacebased inversion with decreasing potential temperature gradient with height. The surface inversion is generally associated with weaker winds. Here, the SBL height is defined as the level where gradient gets smaller than a threshold when starting the search at the lowest level (Fig. S4a). A typical case for strong wind speeds is that a neutral or weakly stable layer is present in the lowest 100$200 \mathrm{~m}$, which is topped by a strong inversion with lessstable or near-neutral conditions above (case 2; Fig. S4b). In this case, the inversion height is determined as the level where the threshold is exceeded by a downward search. The SBL height $h_{T}$ is taken as the height of the lifted inversion. Case 3 is similar to case 2, but there are multiple inversions. In this case, the lowest inversion is taken, and the search is limited to the lowest $500 \mathrm{~m}$. For the IKAPOS NOW study, a threshold of a $2.0 \mathrm{~K}(100 \mathrm{~m})^{-1}$ is taken. Heinemann (1999) uses $1.5 \mathrm{~K}(100 \mathrm{~m})^{-1}$ for a katabatic wind study with aircraft data, while Heinemann and Klein (2002) use $2.0 \mathrm{~K}(100 \mathrm{~m})^{-1}$ for a model study.
For the analysis of the flow dynamics, the Froude number (Fr) is calculated as an integral for the SBL:

$$
\mathrm{Fr}^{2}=\frac{U^{2}}{\frac{g}{\theta_{m}} \Delta \theta_{m} \times h_{T}},
$$

where $U$ is the mean wind speed in the SBL, and $\Delta \theta_{m}$ is the bulk difference of the mean potential temperature in a layer of $200 \mathrm{~m}$ above the SBL height $h_{T}$ and the mean SBL potential temperature $\theta_{m}$. With the use of the bulk Brunt-Väisälä frequency $N$

$$
N^{2}=\frac{g}{\theta_{m}} \frac{\Delta \theta_{m}}{h_{T}},
$$

Fr can be written as $\mathrm{Fr}=U /\left(N \times h_{T}\right)$.

Using the height of the channeling topography $h_{m}$ as a height scale (estimated as $1000 \mathrm{~m}$ for the Smith Sound; see Fig. 1), the mountain Froude number $\mathrm{Fr}_{m}$ is defined as

$$
\mathrm{Fr}_{m}=\frac{U_{m}}{N_{m} \times h_{m}} .
$$

The mountain Froude number is calculated using the mean wind speed and stability for the subcrest layer.

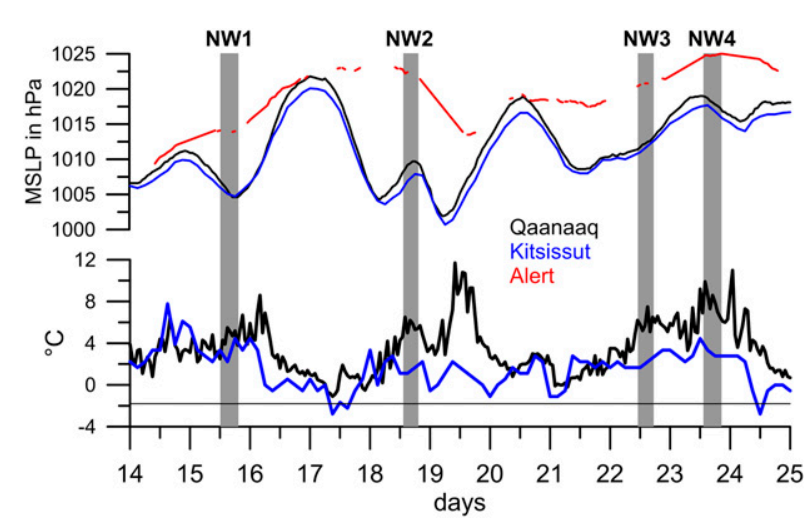

FIG. 2. Overview of the IKAPOS period at Qaanaaq (black), Alert (red), and Kitsissut (blue) during 14-25 Jun 2010. (bottom) Temperature (freezing point of seawater as black line); (top) MSLP. The NOW flight missions are marked by gray bars (see Table 3 ). 

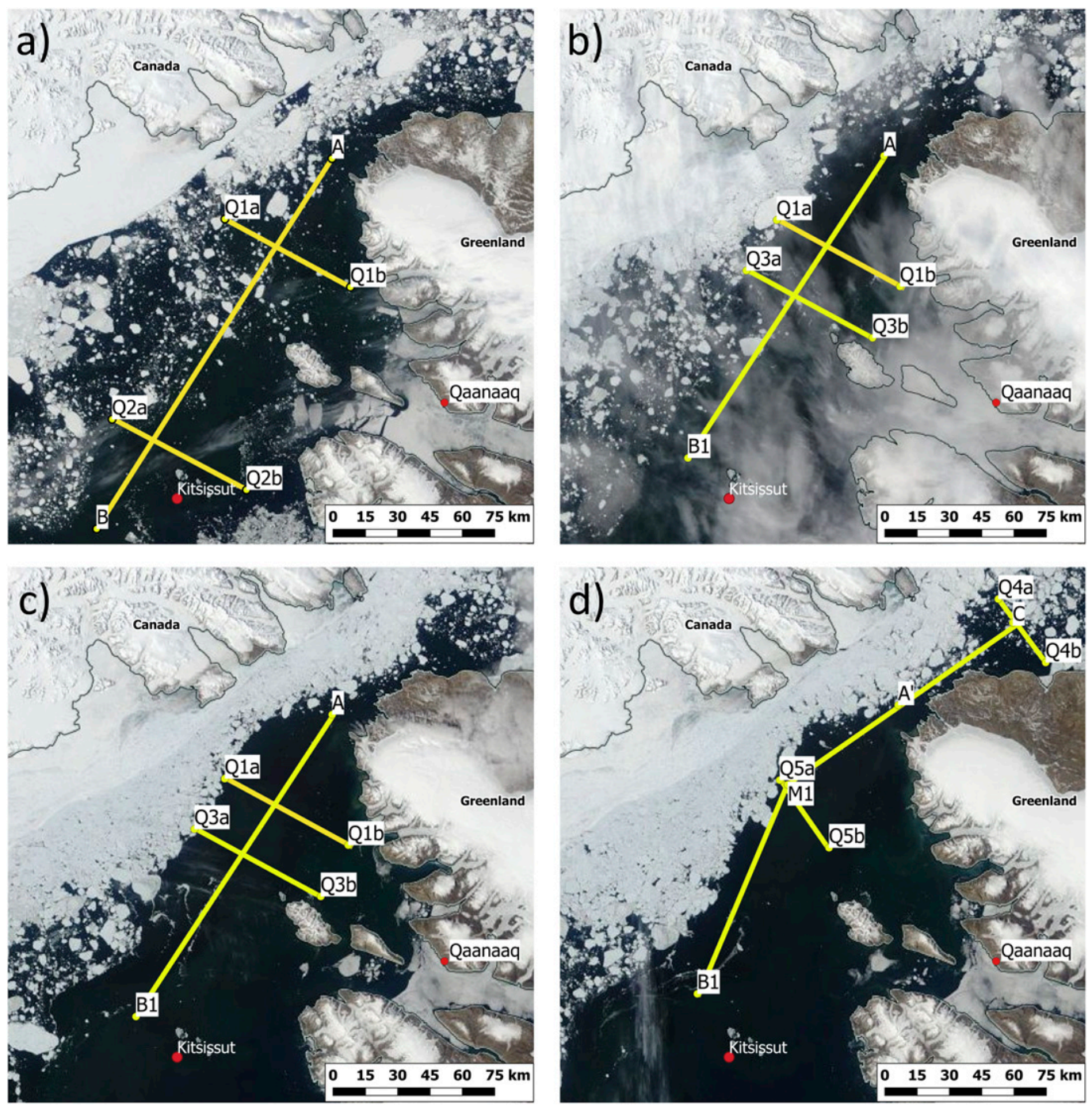

FIG. 3. MODIS satellite images (VIS) with superimposed measurement patterns for the NOW programs. (a) 15 Jun (NW1); (b) 18 Jun (NW2); (c) 22 Jun (NW3); and (d) 23 Jun (NW4). Waypoints are marked.

$\mathrm{Fr}_{m}$ is just the inverse of the normalized mountain height, which is used to describe flow blocking or different flow regimes for gap flows (e.g., Gaberšek and Durran 2004, hereafter GB04). The bulk Brunt-Väisälä frequency is also needed for the computation of the Rossby radius, which is of importance for the adaption of the flow to geostrophic conditions. Since the aircraft profiles do not cover the full subcrest layer, two modified mountain Froude numbers are calculated. The first is $\mathrm{Fr}_{m, \mathrm{SBL}}$, which is calculated using the mean wind speed and stability in the SBL. This is not representative for the whole flow below the height of the topography, but indicates if the SBL flow could pass over or flow around the mountain. Alternatively, the Froude number $\mathrm{Fr}_{m \text {,prof }}$ was calculated using the mean wind speed and stability for the whole height of the aircraft profile $(600-800 \mathrm{~m})$, which is a good approximation to the true mountain Froude number (using the full subcrest layer below $1000 \mathrm{~m}$ ).

\section{d. Additional data}

In addition to the aircraft data, data from synoptic stations in the vicinity of Nares Strait [data sources Danish Meteorological Institute (DMI) and NOAA; https://gis. ncdc.noaa.gov] and digital satellite data (MODIS) have been collected for the period of the experiment.

\section{Overview of the flight missions}

The observations at Qaanaaq (elevation $16 \mathrm{~m}$ ) are shown in Fig. 2 for the period of the experiment. Temperatures are generally around $4^{\circ} \mathrm{C}$, but also exceed $8^{\circ} \mathrm{C}$ for some days. The wind is strongly influenced by the 

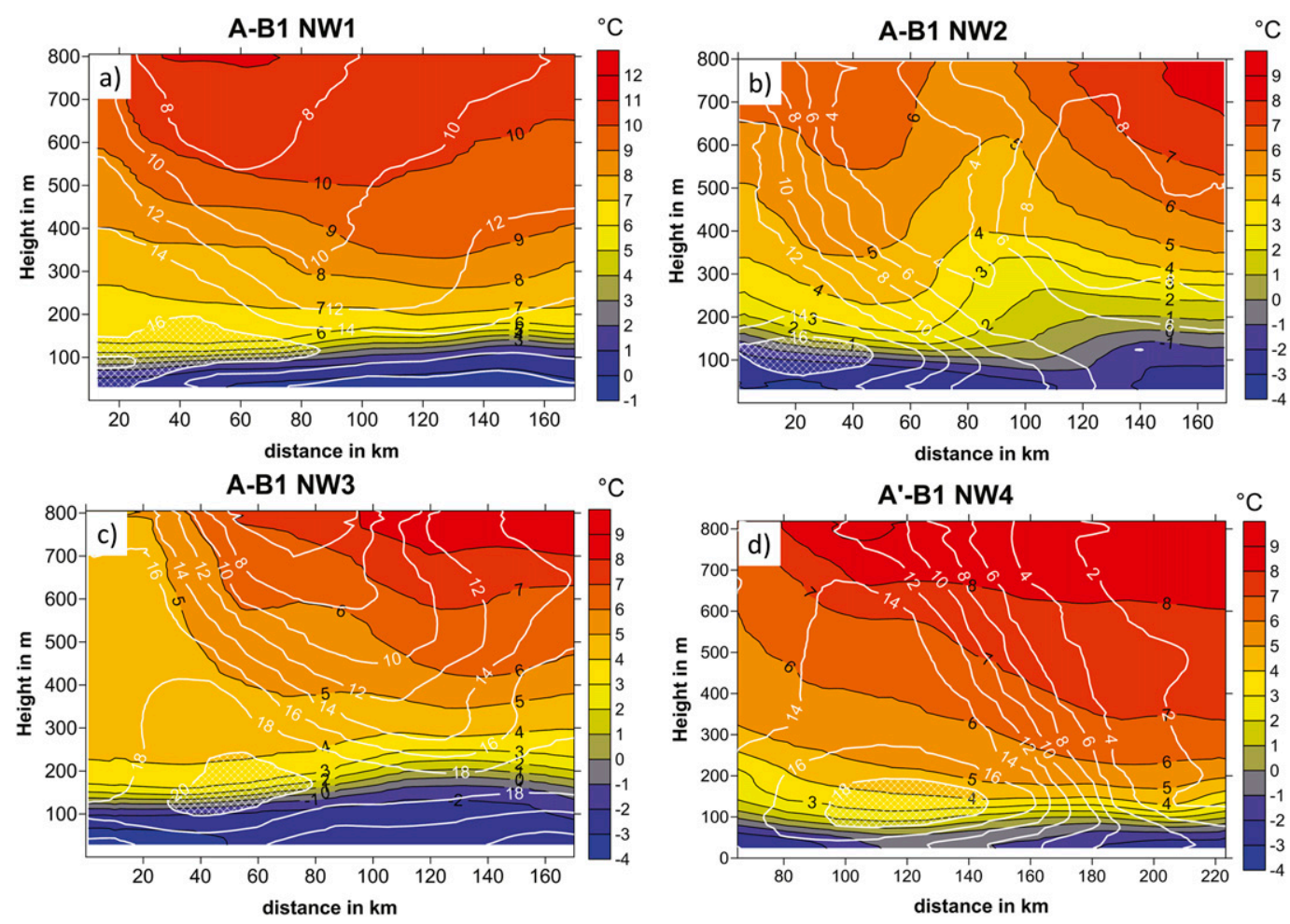

FIG. 4. Cross sections of potential temperature and wind speed along the main profiles starting at Smith Sound exit for (a) NW1, (b) NW2, (c) NW3, and (d) NW4. Distances are given relative to the reference points southward [i.e., point $A$ for (a)-(c) and point $C$ for (d)], where Smith Sound exit is at $70 \mathrm{~km}$ (point $\mathrm{A}^{\prime}$ has almost the same position as point A; see Fig. 3). The view is from the west. Note that (a) has a different temperature scale.

local topography (see Fig. 1), which results in mainly westerly winds (not shown). Figure 2 also includes observations from Alert (elevation $30 \mathrm{~m}$; at the northern end of the Nares Strait; Fig. S2) and Kitsissut (Carey Island; elevation $11 \mathrm{~m}$ ) in the NOW (Fig. 1). While the pressure at Kitsissut is similar to the data of Qaanaaq (but generally slightly lower), the comparison to Alert shows that the NOW flight missions (denoted as NW1-4) were flown during relatively large pressure gradients along the Nares Strait. The winds at Kitsissut (not shown) are also relatively high during the NOW flights. However, wind data of that station have to be taken with caution since there seems to be a problem with the wind sensor (wind direction is from the south the whole month of June). The $2-\mathrm{m}$ temperature at Kitsissut is $3^{\circ}-4^{\circ} \mathrm{C}$ during the NOW flights (i.e., well above the freezing point of seawater).

Figure 3 gives an overview of the NOW flights superimposed on visible MODIS satellite images with 250-m resolution (Fig. S5 shows a 3D view with topography). The flight schedule had a main profile extending from Smith Sound southward and different cross profiles (labeled Q). The flight patterns had to be adapted to flight restrictions, since no permission was obtained by the Canadian Nunavut Research Institute to fly over Canadian territory. The repair of the radiation sensor processor took 2 days, so on 19 and 20 June, no flights could be performed (Table 3). On 11 and 21 June, and from 24 June to the end of the campaign, no takeoffs were possible due to surface fog at Qaanaaq Airport.

The NOW flights were flown under similar synoptic situations (i.e., generally a synoptic low south of Nares Strait and a high north of it). In the area of the Nares Strait, a stable but fully turbulent boundary layer with strong winds of up to $22 \mathrm{~m} \mathrm{~s}^{-1}$ was found during conditions of relatively warm, synoptically induced northerly winds through the Nares Strait. Strong surface inversions were present in the lowest $100-200 \mathrm{~m}$.

The ice situation (Fig. 3) shows that for the first two flights, scattered ice floes were present over the NOW, and Smith Sound was partly ice covered. For flights NW3 and NW4, the ice edge was better defined, and Smith Sound is mainly ice covered. Flights NW1-3 were dedicated to studying the ABL downstream of Smith Sound, and only NW4 was flown also to study the conditions upstream of Smith Sound. The coastal areas of Murchinson Sound and the Inglefield area northwest of Smith Sound (locations marked in Fig. 1) are snow free. 

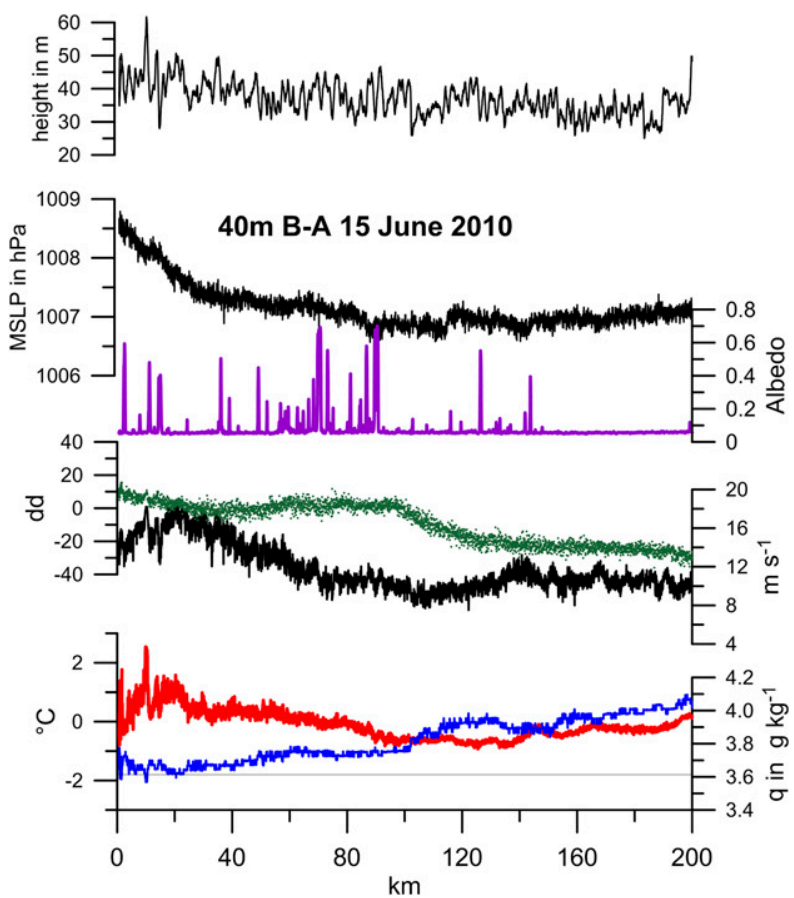

FIG. 5. The 1-Hz data at about 40-m height for 15 Jun (NW1) along flight path A-B (see Fig. 3) for radar height, MSLP, albedo (purple), wind speed (black), wind direction (dd; green dots), temperature (red; freezing point of seawater as black line), and specific humidity (blue). The distances are relative to point $\mathrm{A}$.

A summary of the four flights is given as cross sections of potential temperature and wind speed along the main north-south profile (Fig. 4). The starting and end points for this profile are different for the flights (only identical for NW2 and NW3), and thus the cross sections have been homogenized by choosing point $\mathrm{A}$ as the starting point and point B1 as the end point (Fig. 3). For NW4, the main flight leg C-M1-B1 was different, and the cross section is shown starting at the reference point $\mathrm{A}^{\prime}$ close to point $\mathrm{A}$ (the full cross section is shown in section $3 \mathrm{c}$ ). Only the vertical profiles are used, which were flown between 30 and $800 \mathrm{~m}$ (corresponding to a horizontal distance of about $10 \mathrm{~km}$ between two vertical profiles).

In all four NOW flights, an LLJ was found with the core within a distance of $80 \mathrm{~km}$ from the exit of Smith Sound (point A). The LLJ is associated with a strong inversion at 100-200-m height, which is generally rising north and south of the jet core. The most intense jet was measured for NW3, where the core speed exceeded $20 \mathrm{~m} \mathrm{~s}^{-1}$. While the structure of the lowest $800 \mathrm{~m}$ is relatively similar for the northern $100 \mathrm{~km}$ (resulting from the gap flow through Smith Sound), larger differences can be seen for the southern part of the cross section, which results from a different setting of the synoptic situation (maps from an ERA5 reanalysis are shown in Fig. S6 for each case). For all NOW flights, the low-level air is relatively warm for the whole Nares Strait north of the gap $\left(2^{\circ}-4^{\circ} \mathrm{C}\right)$.

During NW1, the center of a synoptic cyclone was located over Melville Bay (see Fig. S6), and a strong pressure gradient with northerly winds was over the area of the cross section. Figure 2 shows the pressure fall at Qaanaaq by $6 \mathrm{hPa}$ starting at 0000 UTC 15 June, while the pressure was increasing at Alert, resulting in a pressure difference of about $10 \mathrm{hPa}$ along the Nares Strait. This is reflected by the high winds in the southern part for NW1

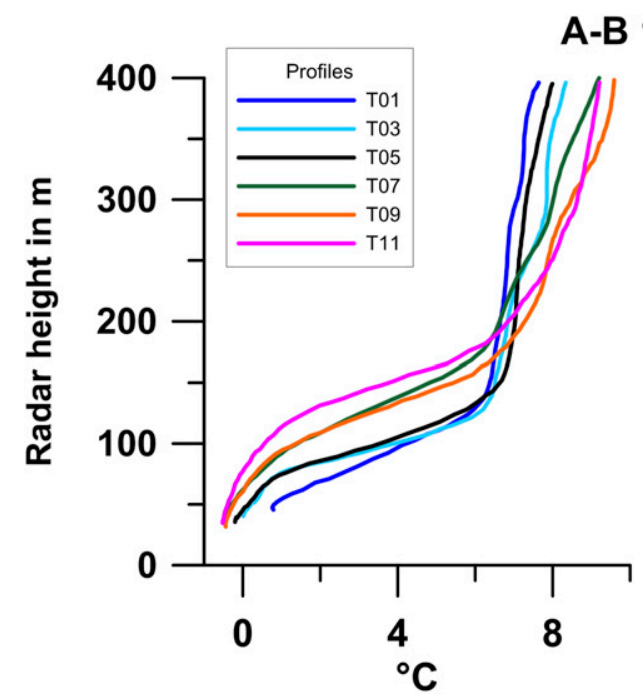

A-B 150610

FIG. 6. Vertical profiles for 15 Jun (NW1) along flight path A-B (see Fig. 3) for (left) potential temperature and (right) wind speed (ff). The distances to point A are 19 (T01), 44 (T03), 68 (T05), 106 (T07), 128 (T09), and $140 \mathrm{~km}$ (T11). Only every second profile is shown for clarity. 


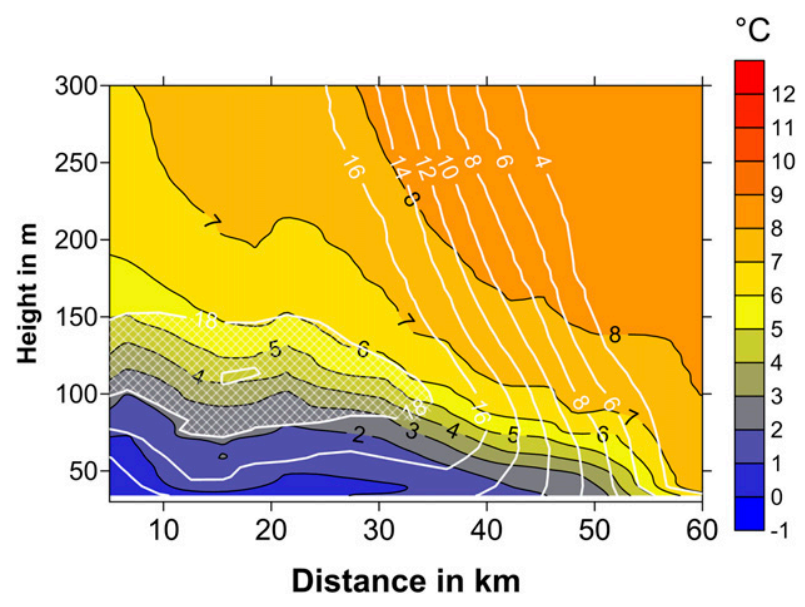

FIG. 7. Cross sections of potential temperature and wind speed (jet core marked by hatching) along the cross profile Q1 (Q2 is shown in the online supplement) for NW1 (see Fig. 3). The view is from the south.

(Fig. 4a), which are almost purely northerly (absolute value of the east wind component less than $2 \mathrm{~m} \mathrm{~s}^{-1}$ ). The same is true for the lowest $200 \mathrm{~m}$ in the northern part (including the LLJ), only above the jet, a slight shift to northeasterly winds was observed.

The situation for NW2 was different than NW1, since the center of the synoptic low was located south of the cross section at $76^{\circ} \mathrm{N}$ (see Fig. S6). As a result, winds in the southern part of the cross section were easterly. The associated advection from the east leads to a change of the thermal structure and the flow field (Fig. 4b), which is no longer related to the processes in the northern part. Thus, this flight is not discussed in detail in the following sections. The pressure difference between Alert and Qaanaaq amounts to about $13 \mathrm{hPa}$.

For NW3, the low was located over Melville Bay as for NW1, but with a broader center that extends to $77^{\circ} \mathrm{N}$ (see Fig. S6). The wind field (Fig. 4c) is also similar to NW1, with mainly northerly winds, with the exception of a shift to a northeasterly wind above $200 \mathrm{~m}$ at point $\mathrm{A}$. The pressure difference between Alert and Qaanaaq amounts to about $8 \mathrm{hPa}$.

NW4 was characterized by a trough extending over Melville Bay and the Qaanaaq area, which leads to weak pressure gradients for the southern part of the cross section (see Fig. S6). Accordingly, the wind speed decreases strongly with distance from point A (Fig. 4d). The pressure difference between Alert and Qaanaaq amounts to about $7 \mathrm{hPa}$.

Three NOW cases-NW1, NW3, and NW4-are now presented in more detail.

\section{a. NW1 (15 June 2010)}

The main flight leg A-B (Fig. 3) starts near Smith Sound and extends about $200 \mathrm{~km}$ southward. Figure 5

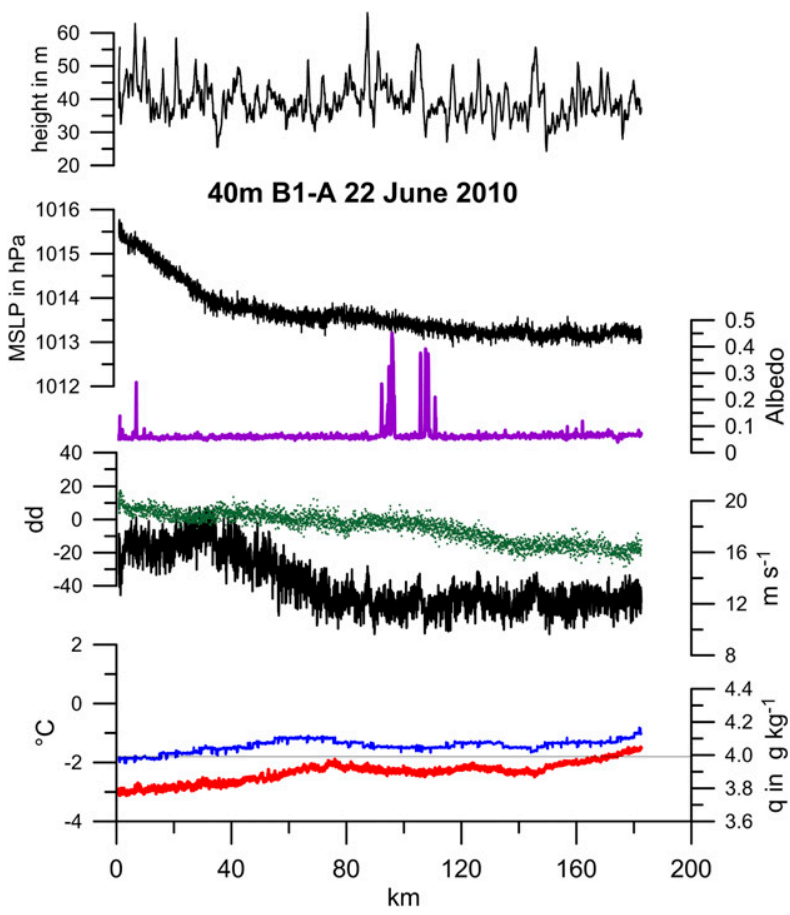

FIG. 8. As in Fig. 5, but for 22 Jun (NW3) along flight path A-B1 (see Fig. 3). The distances are relative to point A.

shows the aircraft data at the lowest flight leg (around $40 \mathrm{~m}$ ) as unfiltered $1-\mathrm{Hz}$ data. As indicated by the albedo, the northern part of the leg has fractional sea ice coverage, while the southern part is ice free. The wind has maximum values of $17-18 \mathrm{~m} \mathrm{~s}^{-1}$ near point $\mathrm{A}$ and decreases toward the south to around $10 \mathrm{~m} \mathrm{~s}^{-1}$. Wind is strictly northerly at Smith Sound $\left(0^{\circ}-10^{\circ}\right)$ and veers slightly by $20^{\circ}$ toward the south. The mean sea level pressure (MSLP) was computed using the radar height and the measured temperature. It shows a maximum at Smith Sound and decreases by $\sim 1.5 \mathrm{hPa}$ in the first $40 \mathrm{~km}$ southward.

Along the northerly flow, a cooling is observed while the specific humidity slightly increases. Thus, the relatively warm air advected from the north is transformed by the interaction with the ocean surface being at the freezing point of ocean water, forming a thermal internal SBL over the NOW. The development of the internal SBL can be best demonstrated in the form of vertical profiles (Fig. 6). For clarity, only every other profile of the first 11 profiles is shown, while the cross section of Fig. 4 includes all profiles. All profiles show a well-developed SBL. The SBL height rises with increasing distance during strong northerly flow, which shows the LLJ for all profiles. A distinct cooling with increasing distance is observed in the SBL, which indicates that turbulence generated by the strong wind shear mixes cool surface air to higher layers (i.e., a 


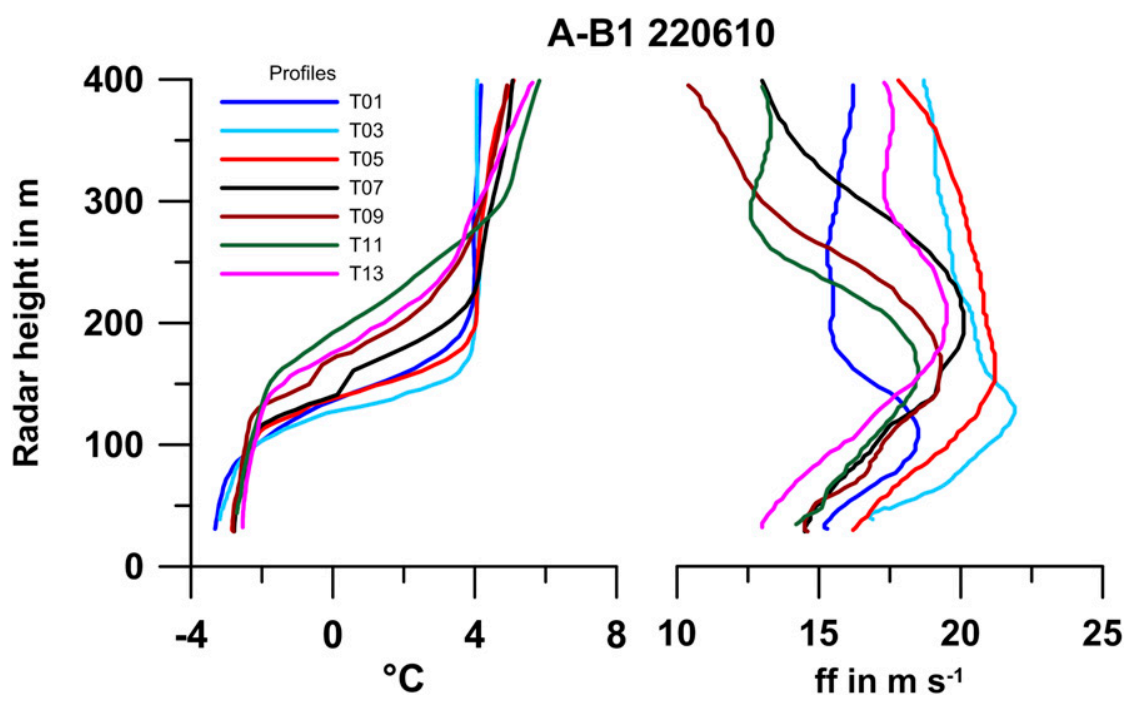

FIG. 9. Vertical profiles for 22 Jun (NW3) along flight path A-B1 (see Fig. 3) for (left) potential temperature and (right) wind speed (ff). The distances to point A are 5 (T01), 30 (T03), 55 (T05), 80 (T07), 100 (T09), 125 (T11), and $150 \mathrm{~km}$ (T13). Only every second profile is shown for clarity.

negative sensible heat flux increasing with height). Because of the mixing, the lowest layers become less stable with increasing distance downwind.

The 3D structure of the LLJ was investigated by the cross profiles Q1 and Q2 (see Fig. 3 for positions). The vertical profiles on these cross profiles were lower than on the A-B leg, and a vertical profile is available every $3 \mathrm{~km}$ over a distance of $60 \mathrm{~km}$. Q1 lies at the exit of Smith Sound and shows the shading effect of the Greenland Mountains on the flow (Fig. 7). Wind speed decreases from $20 \mathrm{~m} \mathrm{~s}^{-1}$ in the jet core to less than $4 \mathrm{~m} \mathrm{~s}^{-1}$ in the lee of the mountains. This is associated with a distinct temperature gradient of more than $5 \mathrm{~K}$ in $30 \mathrm{~km}$. At the second cross section, Q2 (about $100 \mathrm{~km}$ downstream of Q1), the wind speed at the jet core has decreased to $16 \mathrm{~m} \mathrm{~s}^{-1}$, and the shading effect is also much weaker (Fig. S7).

\section{b. NW3 (22 June 2010)}

The main flight leg A-B1 (Fig. 3) starts near Smith Sound and extends about $200 \mathrm{~km}$ southward. Figure 8 shows the aircraft data at the lowest flight leg (around $40 \mathrm{~m}$ ). Only a little fractional sea ice coverage is present. The wind has values of $12 \mathrm{~m} \mathrm{~s}^{-1}$ in the southern part and increases to $16 \mathrm{~m} \mathrm{~s}^{-1}$ near Smith Sound. As with NW1, it is almost strictly northerly at Smith Sound and veers slightly by $20^{\circ}$ toward the south. The MSLP is again highest at Smith Sound and shows a slightly higher decrease than NW1 in the first $40 \mathrm{~km}$ southward $(\sim 2.0 \mathrm{hPa})$.

In contrast to NW1, the air temperature at $40 \mathrm{~m}$ is lower than the freezing point of seawater, indicating slightly unstable conditions. This is also reflected by the vertical profiles (Fig. 9). An almost well-mixed layer is present below $100 \mathrm{~m}$, which rises to about $150 \mathrm{~m}$ at distance of $150 \mathrm{~km}$ from Smith Sound. Again, the LLJ structure can be seen, starting at Smith Sound with a height at $100 \mathrm{~m}$, and with a maximum speed of $\sim 22 \mathrm{~m} \mathrm{~s}^{-1}$ located $50 \mathrm{~km}$ downstream of Smith Sound (see Fig. 4c). With the growth of the inversion base, the LLJ broadens and rises to $200 \mathrm{~m}$. The wind direction of the profiles at low levels (not shown) is $0^{\circ}$ at Smith Sound and changes to $340^{\circ}$ in the southern part of the leg, which is in agreement with the 40-m data. All profiles show a turning of the wind with height by $20^{\circ}-30^{\circ}$ in the lowest $400 \mathrm{~m}$.

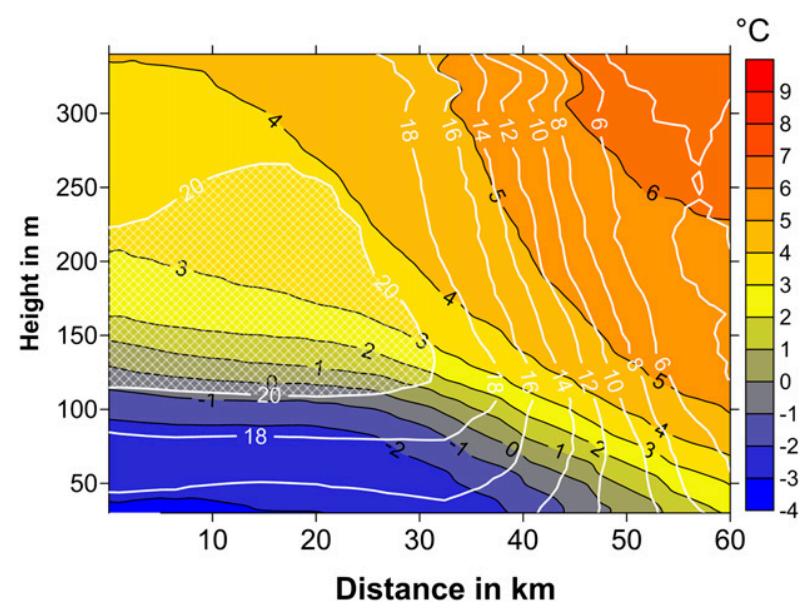

FIG. 10. As in Fig. 7, but for NW3. Q3 is shown in the online supplement. 

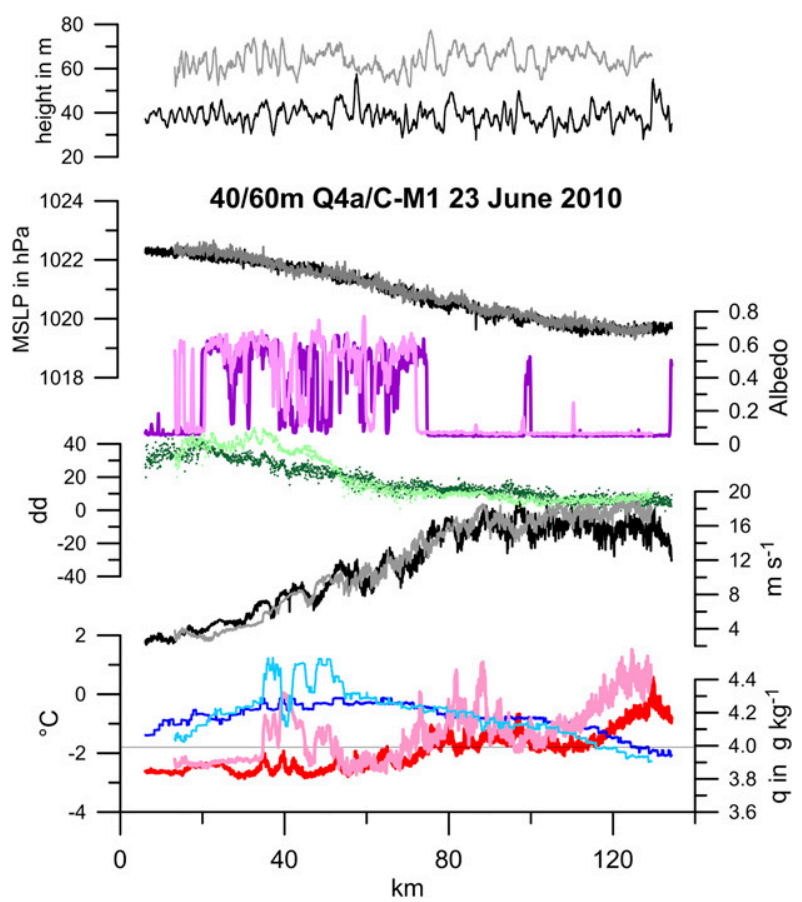

FIG. 11. As in Fig. 5, but for C-M1 at $60 \mathrm{~m}$ (dark colors) and Q4a-M1 at $40 \mathrm{~m}$ (light colors) for 23 Jun (NW4; see Fig. 3). The distances are relative to point $\mathrm{C}$.

As with NW1, the 3D structure of the LLJ was investigated by the cross profiles Q1 and Q3 (see Fig. 3 for positions). Again, Q1 lies at the exit of Smith Sound and shows the shading effect of the Greenland Mountains on the flow (Fig. 10). Wind speed decreases from $20 \mathrm{~m} \mathrm{~s}^{-1}$ in the jet core to less than $6 \mathrm{~m} \mathrm{~s}^{-1}$ in the lee of the mountains. This is associated with a distinct temperature gradient of about $3 \mathrm{~K}$ in $40 \mathrm{~km}$. The second cross section Q3 is now closer to Q1 (compared to Q2) and shows the welldeveloped jet core with more than $22 \mathrm{~m} \mathrm{~s}^{-1}$ between 150 and $200 \mathrm{~m}$ (Fig. S8). Again, the shading effect can be seen.

\section{c. NW4 (23 June 2010)}

During NW4, measurements also took place north of Smith Sound in order to study the full transition process for the LLJ development. Therefore, the main flight leg C-M1 (Fig. 3) starts in the Kane Basin with Smith Sound at its center. The flight leg was then extended southward to point B1, which corresponds to a total length of $200 \mathrm{~km}$. The shape of the flight leg results from the fact that point M1 is almost at the Canadian border (which could not be crossed). Cross sections Q4 and Q5 are perpendicular to this flight leg, with the location of Q5 comparable to Q3 of NW3. Two low-level legs were flown through Smith Sound: C-M1 at $60 \mathrm{~m}$ and Q4a-M1 at $40 \mathrm{~m}$. Figure 11 shows the aircraft data of these two flight legs. The albedo data indicate high sea ice concentration north of Smith Sound and only a little ice south of it. The wind starts with low values of $4 \mathrm{~m} \mathrm{~s}^{-1}$ in the Kane Basin and accelerates to $16 \mathrm{~m} \mathrm{~s}^{-1}(40 \mathrm{~m})$ and $18 \mathrm{~m} \mathrm{~s}^{-1}(60 \mathrm{~m})$ near Smith Sound. Temperatures are increasing in this strong wind zone, while the humidity values slightly decrease. This indicates that apart from warming from the ocean surface, additional warming by vertical motions might be present. The MSLP reflects

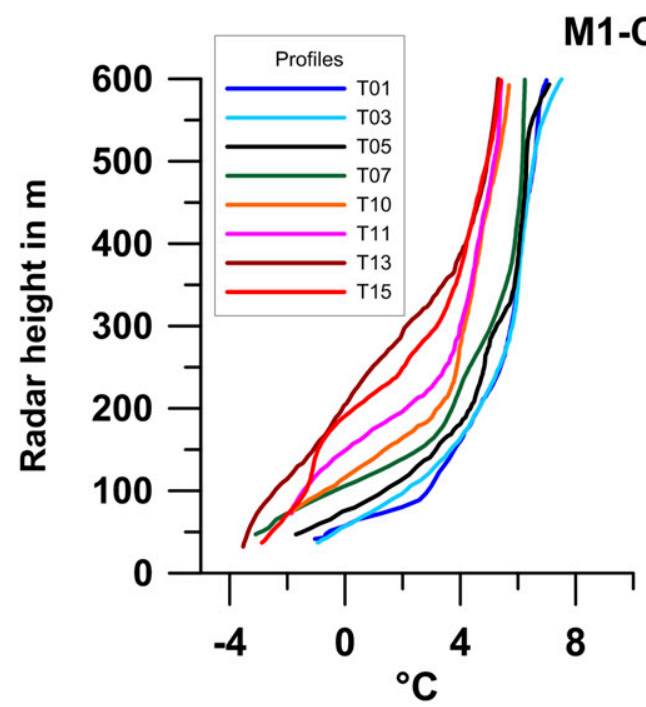

FIG. 12. As in Fig. 6, but for 23 Jun (NW4) along flight path M1-C (see Fig. 3) The distances to point $\mathrm{C}$ are 125 (T01), 110 (T03), 90 (T05), 75 (T07), 50 (T10), 40 (T11), 25 (T13), and $5 \mathrm{~km}$ (T15). In contrast to Fig. 6, the profiles were flown from south to north. Smith Sound exit is at $70 \mathrm{~km}$ (T07); profiles T13 and T15 are upstream of Smith Sound. 


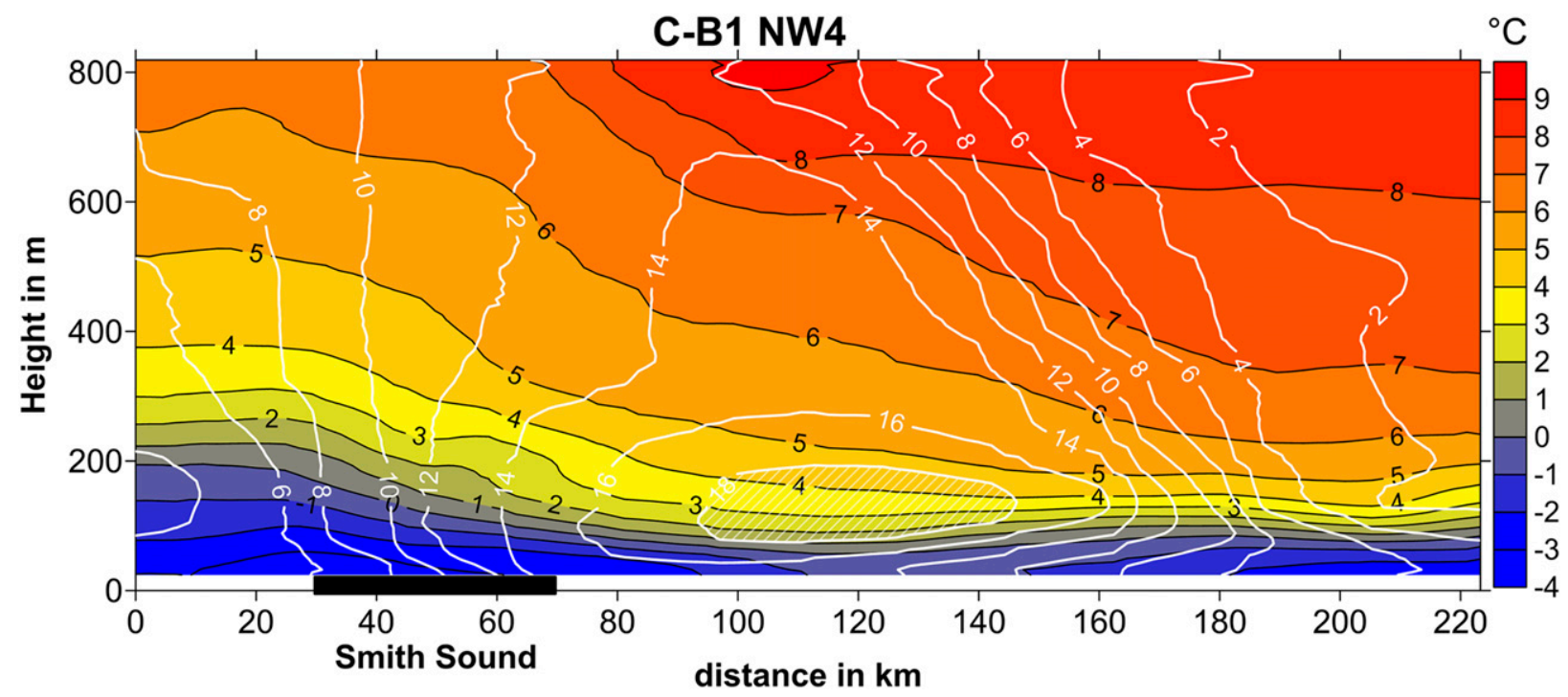

FIG. 13. Cross sections of potential temperature and wind speed (jet core marked by hatching) along the line C-B1 for NW4 (see Fig. 3). The view is from the west; the location of Smith Sound is indicated.

now the gradient between the Kane Basin and Smith Sound exit with a gradient of $\sim 2 \mathrm{hPa}(100 \mathrm{~km})^{-1}$.

The vertical profiles are shown in Fig. 12 along the line M1-C starting south of Smith Sound and ending in the Kane Basin. In the Kane Basin, relatively low winds and a homogeneous wind distribution are present in the lowest $600 \mathrm{~m}$. The wind accelerates with decreasing distance to Smith Sound, which is located between 30 - and $70-\mathrm{km}$ distance from point $\mathrm{C}$. The corresponding wind profiles show the formation of the LLJ in the Smith Sound, but also the further acceleration southward. The profiles of the potential temperature show that the channeling takes place in a stably stratified boundary layer and is associated with a warming of $2 \mathrm{~K}$ in the lowest $300 \mathrm{~m}$ (note that the real temperatures at the lowest levels as shown in Fig. 12 are higher due to a surface pressure well above $1000 \mathrm{hPa}$ ). With the development of the LLJ, an intensification of the surface inversion takes place. The full picture of the LLJ structure can be seen in Fig. 13. The maximum intensity of the LLJ with more than $18 \mathrm{~m} \mathrm{~s}^{-1}$ is located at $30-80-\mathrm{km}$ distance to the exit of Smith Sound. The lowering of the inversion over and behind Smith Sound indicates the three-dimensional channeling process, which affects the lowest $800 \mathrm{~m}$ of the atmosphere. This is consistent with the fact that the topography shown in Fig. 1 shows the Greenlandic Mountain barrier with a top of around $1000 \mathrm{~m}$.

The 3D structure of the LLJ was investigated by the cross profiles Q4 and Q5 (see Fig. 3 for positions). Q5 lies at the exit of Smith Sound (similar to Q3 of NW3), while Q4 lies in the Kane Basin. The Q4 cross section
(Fig. 14) shows the relatively low wind speeds and a relatively high inversion, but also east-west gradients of wind and temperature. The top of the surface inversion is about $400 \mathrm{~m}$ near the Greenland coast (Q4b) and decreases to $150 \mathrm{~m}$ near the middle of the Kane Basin (Q4a). Wind speeds are between 6 and $8 \mathrm{~m} \mathrm{~s}^{-1}$ and increase to values of $10-14 \mathrm{~m} \mathrm{~s}^{-1}$ near Q4a, which indicates the partial blocking of the flow in the eastern part and possibly the beginning of channeling by the topography of Ellesmere Island. The cross profile Q5 starts west of the center of the LLJ and shows the jet core with more than $19 \mathrm{~m} \mathrm{~s}^{-1}$ at $130-\mathrm{m}$ height and again the shading effect of the Greenland Mountains. Wind speed decreases to less than $3 \mathrm{~m} \mathrm{~s}^{-1}$ in the lee of the mountains, again associated with a distinct warming. The temperature structure east of the LLJ (at distance $30-40 \mathrm{~km}$ ) exhibits a local instability at $100-\mathrm{m}$ height, which gives reason to a further investigation of the single vertical profiles (Fig. 15). It has to be noted that the profiles are not strictly vertical, but slantwise over a horizontal distance of about $5 \mathrm{~km}$. While there is a consistent warming at upper levels when moving from the LLJ to the east, a slight cooling is present below $150 \mathrm{~m}$ between profiles T03 and T04/T05, followed by a warming in T06. This results in the local instability as an interpolation effect, but it can be also speculated that the profiles are influenced by gravity waves in the lee of the mountain ridge. This is further indicated by data of the constant-level legs at Q5 (Fig. 16). While the low-level leg $(40 \mathrm{~m})$ shows a relatively smooth transition in the temperature from slightly warmer conditions beneath the jet core to colder conditions in the lee of the mountains (the 

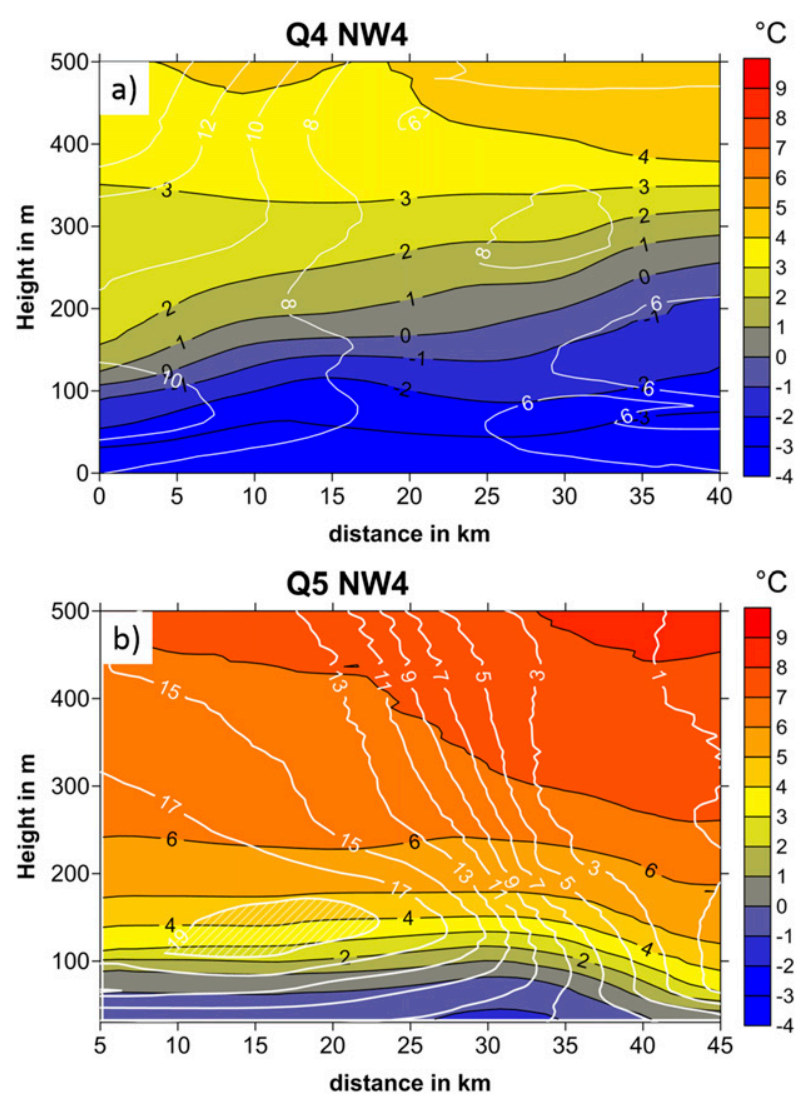

FIG. 14. Cross sections of potential temperature and wind speed (jet core marked by hatching) along the cross profiles (a) Q4 and (b) Q5 for NW4 (see Fig. 3). The view is from the south.

jet core is at about 130-m height and at a distance of $15-20 \mathrm{~km}$ from Q5a; see Fig. 14), large variations of the temperature are observed at the leg at $100 \mathrm{~m}$. The temperature changes can only partly be explained by variations of the aircraft height, particularly the large temperature change at $30-\mathrm{km}$ distance. This is the region between profiles T04 and T05 discussed above. The comparison of the MSLP from Q5 with Q4 shows an almost constant pressure difference of $3 \mathrm{hPa}$ for the cross sections.

\section{Dynamics of the LLJ}

The dynamics of the LLJ is investigated in the framework of the gap flow theory. The numerical experiments of GB04 show that the mountain Froude number is the critical parameter in determining the location of the LLJ with respect to the gap and that the LLJ is a result of a $3 \mathrm{D}$ channeling associated with a decrease of the ABL height. The IKAPOS observations support these findings. The following evaluations focus on NW4, since this case covers the full SBL structure also upstream of the gap.
In a first step, the SBL height is determined from the temperature profiles (see section 2). The SBL height is used to calculate the Froude number using the wind speed averaged over the SBL height (see section 2). In addition, the modified mountain Froude number $\mathrm{Fr}_{m, \mathrm{SBL}}$ is calculated using the mean wind speed and stability in the SBL upwind of the mountain gap using the height of the channeling topography (estimated as $1000 \mathrm{~m}$ ) as height scale. Since $\mathrm{Fr}_{m, \mathrm{SBL}}$ represents the conditions of the SBL, it indicates if this shallow layer could pass over or flow around the topography. To represent the complete upstream flow, the Froude number $\mathrm{Fr}_{m \text {,prof }}$ was calculated using the mean wind speed and stability for the whole profile height $(800 \mathrm{~m}$ for flight path C-M1 and $600 \mathrm{~m}$ for cross profile Q4).

Figure 17 shows the ABL height, mean ABL wind speed, and Froude numbers from profiles along the flight path C-M1 and Q4 for NW4. The Froude number shows a transition from being below 1 upstream of Smith Sound to values larger than 1 inside Smith Sound. This means that the flow changes from tranquil (subcritical) flow to shooting (supercritical) flow conditions (Ball 1956). The shooting flow downstream of the gap has the potential to adjust to the conditions over the NOW in a hydraulic jump (which was not observed during the NOW flights). The SBL height shows a general decrease from $300-350$ to $150-200 \mathrm{~m}$ for the high wind speed region, which results in Froude numbers of 3-4. The Froude numbers $\mathrm{Fr}_{m, \mathrm{SBL}}$ and $\mathrm{Fr}_{m \text {,prof }}$ are only shown for the profiles upstream of the gap. The difference between both Froude numbers is relatively small for the profiles along $\mathrm{C}-\mathrm{M} 1$, and values are between 0.3 and 0.5 . For $\mathrm{Q} 4$, the values for $\mathrm{Fr}_{m \text {,prof }}$ are in the range of $0.4-0.8$ and reflect the wind speed increase toward point $\mathrm{Q} 4 \mathrm{a}$.

These observations fit to the model results of GB04, who show that the location of the jet depends on the mountain Froude number. GB04 performed idealized gap flow simulations for different normalized mountain heights $\varepsilon$ $(0.25,1.4,2.8,5)$ corresponding to mountain Froude numbers $\operatorname{Fr}_{m}(4,0.7,0.36,0.2)$ for the (undisturbed) upstream flow. GB04 identified three different flow regimes. For $\varepsilon=0.25$, there is almost no amplification of the gap flow. For $\varepsilon=5$, upstream blocking occurs, and the flow cannot pass the ridges of the gap. The largest increase of the flow occurs in the gap due to lateral convergence. The channeling leads to a wind maximum inside the gap with an amplification of 1.6 with respect to the undisturbed upstream wind speed (or 2.2 relative to speed in front of the gap). For $\varepsilon=1.4$, the mountain wave regime, a net acceleration of the gap wind occurs within the exit region. The jet maximum is located downstream of the gap exit with an amplification of almost 3 relative to speed in front of the gap. For this regime, the flow acceleration is associated with downward transport by the mountain 


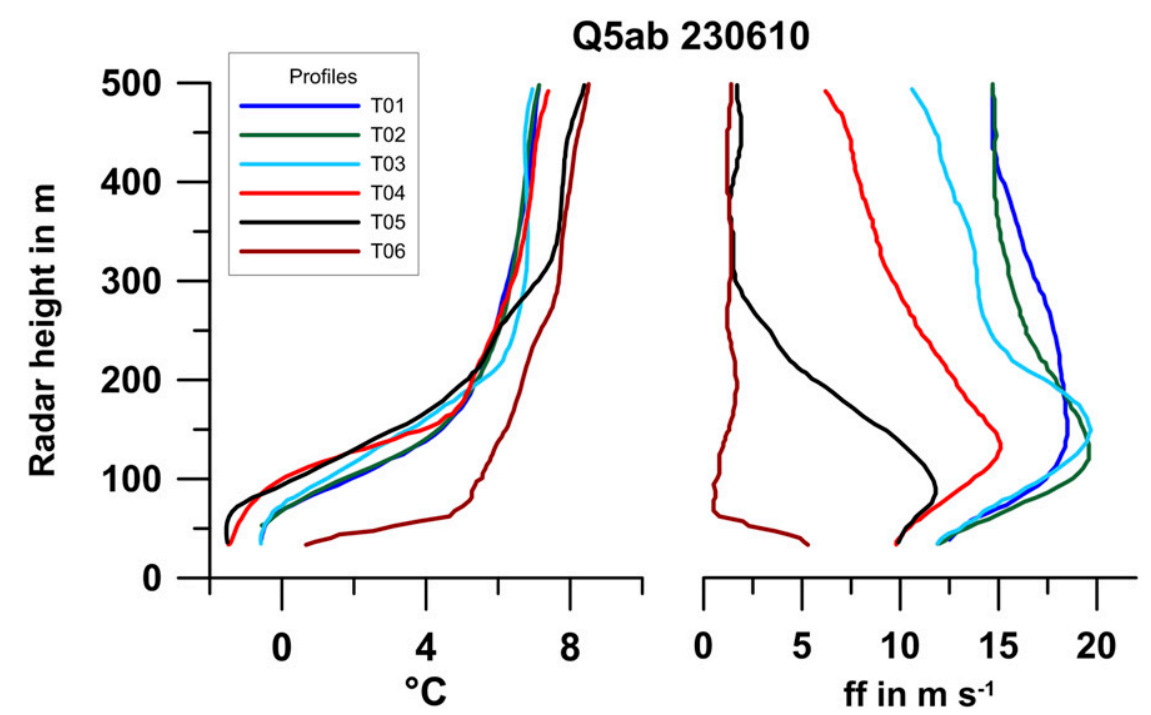

FIG. 15. As in Fig. 6, but for 23 Jun (NW4) along flight path Q5. The distances to point Q5a are 8 (T01), 14 (T02), 21 (T03), 28 (T04), 35 (T05), and 42 km (T06).

wave above the lee slopes of the topography. Along the gap axis, isentropes show a strong decrease with height. The case with $\varepsilon=2.8$ is an intermediate case with a wind maximum at the gap exit and slightly weaker amplification, compared to the mountain wave regime.

Although the conditions during the IKAPOS experiment are much more complex than the idealized simulations of GB04, several features are consistent with their results. The LLJs during IKAPOS are all located downstream of the gap exit, ranging from a distance of 20 (NW1) to $50 \mathrm{~km}$ (NW4). Upstream flow conditions are only documented for NW4, and they show the decrease in SBL height and the amplification of the flow speed by a factor of 3 (Figs. 13, 17). The mountain Froude numbers at the gap entrance are between 0.3 and 0.8 , which is close to the condition of the mountain wave regime. The presence of a mountain wave above the lee slopes associated with the mountain overflow on the Greenlandic side is a possible explanation of the temperature gradient along Q1 (Figs. 7, 10). The increase of the wave amplitude with increasing distance to the center of Smith Sound leads to increased adiabatic warming. Mayr et al. (2007) state that the descent of the air in gap flows caused by the topography can also be understood as a special case of foehn. A combination of foehn and gap flow is also found by Elvidge et al. (2015).

For a characterization of the flow channeling, Overland (1984) introduced an along-strait Rossby number

$$
R_{w}=\frac{U}{f \times W_{m}},
$$

with $f$ the Coriolis parameter and $W_{m}$ the width of the channel. Taking the width of Smith Sound as $50 \mathrm{~km}$, the along-strait Rossby number is about 3 for the situation of NW4. With a Rossby radius between 80 and $100 \mathrm{~km}$, these conditions are consistent with a gap flow
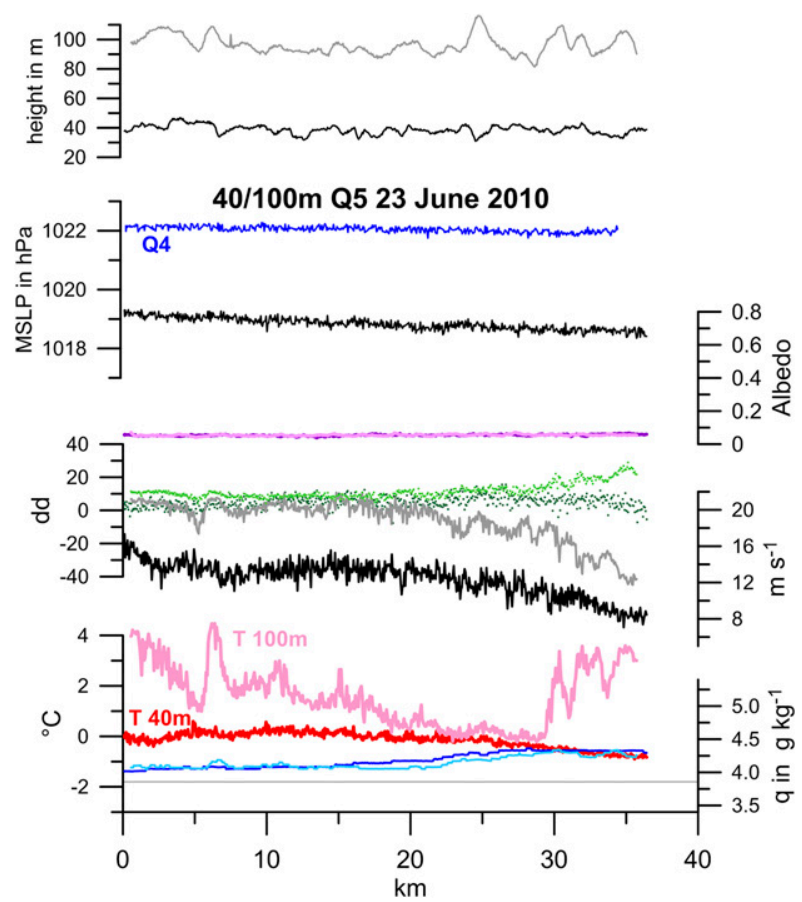

FIG. 16. As in Fig. 5, but for Q5 at $40 \mathrm{~m}$ (dark colors) and at $100 \mathrm{~m}$ (light colors) for 23 Jun (NW4). The distances are relative to point Q5a. In addition, the MSLP for Q4 is shown. 


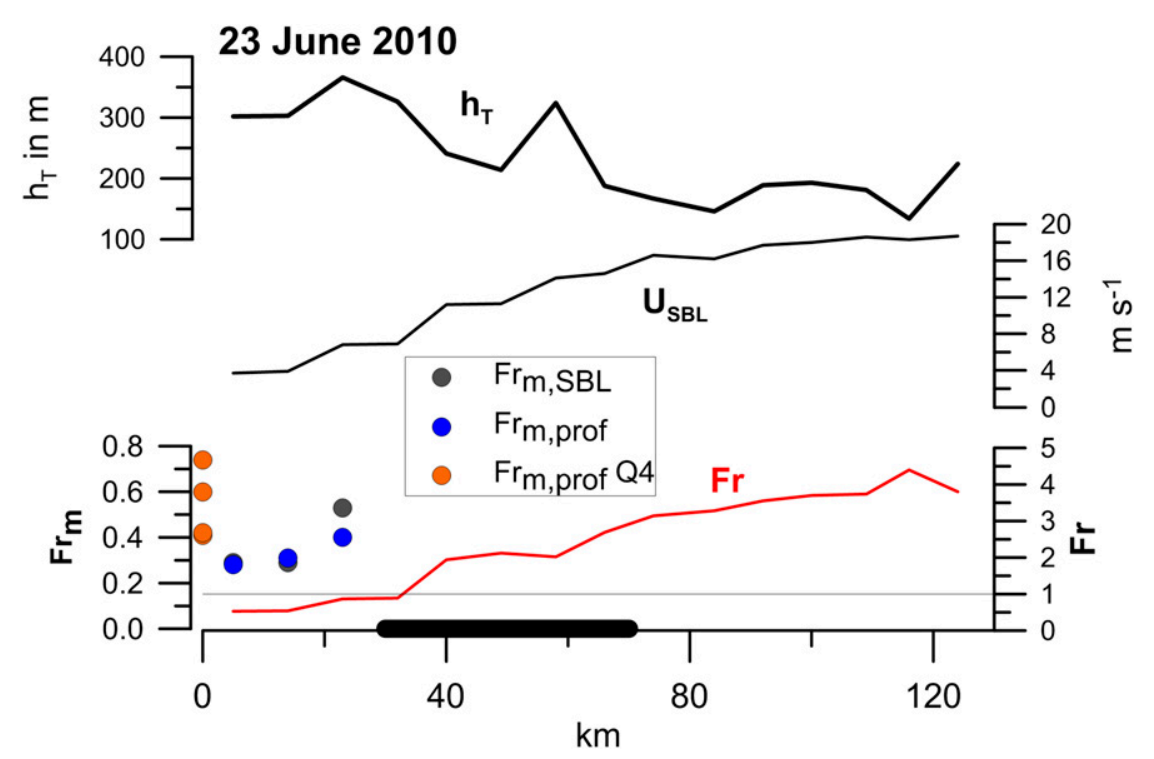

FIG. 17. (top) SBL height, (middle) mean SBL wind speed, and (bottom) Froude numbers from profiles along the flight path C-M1 and Q4 for 23 Jun (NW4, see Fig. 3). The distances are relative to point $\mathrm{C}$; Smith Sound is marked by a bar. The red line marks the Froude number for the SBL, and the gray and blue dots are the mountain Froude numbers (mountain height $1000 \mathrm{~m}$ ) upstream of Smith Sound using conditions of the SBL $\left(\mathrm{Fr}_{m, \mathrm{SBL}}\right)$ and the whole profile height of $800 \mathrm{~m}\left(\mathrm{Fr}_{m}\right.$,prof $)$. Orange dots are mountain Froude numbers of vertical profiles along Q4 (profile height of $600 \mathrm{~m}$ ).

driven by the pressure gradient along the Nares Strait (Overland 1984).

\section{Summary and conclusions}

The IKAPOS experiment yields a valuable dataset of a fully turbulent SBL in gap flow winds over the NOW during summer. This is the first aircraft campaign under such conditions in the Arctic. Four NOW flights with aircraft measurements of LLJs were successfully performed. Constant-level legs and vertical profiles were flown in order to study the 3D structure of the ABL in the region of Smith Sound. The pressure difference between the northern and southern ends of the Nares Strait was between 6 and $13 \mathrm{hPa}$ for the flights. A direct measurement of the pressure gradient across Smith Sound is available for one flight and shows a difference of $3 \mathrm{hPa}$ for a well-developed LLJ with $20 \mathrm{~m} \mathrm{~s}^{-1}$.

The LLJs during IKAPOS are all located downstream of the gap exit, ranging from a distance of 20 to $50 \mathrm{~km}$. The analysis of the dynamic conditions shows that the LLJ formation is consistent with the mountain wave regime for the gap flow dynamics according to GB04.

The high-resolution vertical profiles of the aircraft have been used for detailed analyses of the ABL structure. The northerly flow generally leads to the development of an internal thermal boundary layer past the gap. The cross sections perpendicular to the gap show the effect of the partial flow blocking by the mountains. Simulations using a weather forecast model with $1-\mathrm{km}$ resolution for the NOW flights (not shown) confirm that the LLJ is a result of a $3 \mathrm{D}$ channeling process and that the thermal structure is strongly influenced by the mountain waves above the lee slopes.

Gap flows are observed also in other regions (e.g., Barstad and Adakudlu 2011; Sharp and Mass 2004; Colle and Mass 2000), but for the Nares Strait, orographically channeled flows play a key role for the largest iceproducing polynya in the Arctic. For the sea ice export from the Nares Strait to Baffin Bay and the formation of the North Water polynya, as well as for the ocean circulation, the local intensification of the wind field by the gap flow is of crucial importance.

The aircraft data of the IKAPOS campaign have a large potential for further studies of orographically channeled flows at the Nares Strait. For this crucial region, the IKAPOS data of the 3D structure of the ABL at the interface of sea ice/ocean represent a valuable verification dataset for regional climate models.

Acknowledgments. This work was supported by the Deutsche Forschungsgemeinschaft (DFG) by Grant He2740/9. The aircraft program was funded by the 
Alfred Wegener Institute (AWI). Thanks go to Gerit Birnbaum, Martin Gehrmann, Andreas Herber, Manuel Sellmann, and Daniel Steinhage (all AWI) for help and support during the preparation phase. Heinz Finkenzeller (AWI) is acknowledged for organizing the experiment logistics. The permission for research flights over the Greenlandic part of the North Water, the Humboldt Glacier, and the Kochkyst was given by the Ministry of Housing, Infrastructure, and Transport in Greenland. For support during the experiment, thanks go to the Danish Meteorological Institute (DMI) for comprehensive weather information and to the personnel at Qaanaaq Airport for help and support. Data from synoptic weather stations were provided by DMI and NOAA, and MODIS satellite data are from NASA. The IKAPOS field experiment participants were the pilots Keith Krueger and Erik Bengtsson, the flight engineer Michael McCrae (all Kenn Borek Air Ltd., Canada), the instrument operators Johannes Käßbohrer (FIELAX) and Christoph Petersen (AWI), and the researchers Günther Heinemann (mission leader) and Thomas Ernsdorf (both University of Trier). I thank also Kenn Borek Air for support in the unsuccessful application at Nunavut Research Institute (NRI) for flight permission over the Canadian part of the North Water. Special thanks go to Clemens Drüe for processing and calibration of the raw aircraft data, to Thomas Ernsdorf for the first data evaluations and collection of data from surface stations, and to Svenja Kohnemann for plotting ERA5 weather charts.

\section{REFERENCES}

Ball, F. K., 1956: The theory of strong katabatic winds. Aust. J. Phys., 9, 373-386, https://doi.org/10.1071/PH560373.

Barber, D. G., J. M. Hanesiak, W. Chan, and J. Piwowar, 2001: Sea-ice and meteorological conditions in northern Baffin Bay and the North Water polynya between 1979 and 1996. Atmos.-Ocean, 39, 343-359, https://doi.org/10.1080/07055900.2001.9649685.

Barstad, I., and M. Adakudlu, 2011: Observation and modelling of gap flow and wake formation on Svalbard. Quart. J. Roy. Meteor. Soc., 137, 1731-1738, https://doi.org/10.1002/qj.782.

Colle, B. A., and C. F. Mass, 2000: High-resolution observations and numerical simulations of easterly gap flow through the Strait of Juan de Fuca on 9-10 December 1995. Mon. Wea. Rev., 128, 2398-2422, https://doi.org/10.1175/1520-0493(2000)128<2398: HROANS $>2.0 . \mathrm{CO} ; 2$.

Drüe, C., and G. Heinemann, 2013: A review and practical guide to in-flight calibration for aircraft turbulence sensors. J. Atmos. Oceanic Technol., 30, 2820-2837, https://doi.org/10.1175/ JTECH-D-12-00103.1.

Elvidge, A. D., I. A. Renfrew, J. C. King, A. Orr, T. A. LachlanCope, M. Weeks, and S. L. Gray, 2015: Foehn jets over the Larsen C Ice Shelf, Antarctica. Quart. J. Roy. Meteor. Soc., 141, 698-713, https://doi.org/10.1002/qj.2382.

Gaberšek, S. A., and D. R. Durran, 2004: Gap flows through idealized topography. Part I: Forcing by large-scale winds in the nonrotating limit. J. Atmos. Sci., 61, 2846-2862, https://doi.org/ 10.1175/JAS-3340.1.

Gutjahr, O., and G. Heinemann, 2018: A model-based comparison of extreme winds in the Arctic and around Greenland. Int. J. Climatol., https://doi.org/10.1002/joc.5729, in press.

Heinemann, G., 1999: The KABEG'97 field experiment: An aircraft-based study of katabatic wind dynamics over the Greenland Ice Sheet. Bound.-Layer Meteor., 93, 75-116, https://doi.org/10.1023/A:1002009530877.

_ 2002: Aircraft-based measurements of turbulence structures in the katabatic flow over Greenland. Bound.-Layer Meteor., 103, 49-81, https://doi.org/10.1023/A:1014537229865.

, and T. Klein, 2002: Modelling and observations of the katabatic flow dynamics over Greenland. Tellus, 54A, 542-554, https://doi.org/10.1034/j.1600-0870.2002.201401.x.

, T. Ernsdorf, and C. Drüe, 2011: Investigation of Katabatic Winds and Polynyas during Summer-IKAPOS: Field phase report. Helmholtz Gemeinschaft Reports on Polar and Marine Research 633, 125 pp., http://epic.awi.de/29945/1/ Hei2011c.pdf.

Ito, H., 1982: Wind through a channel-Surface wind measurements in Smith Sound and Jones Sound in northern Baffin Bay. J. Appl. Meteor., 21, 1053-1062, https://doi.org/10.1175/ 1520-0450(1982)021<1053:WTACWM >2.0.CO;2.

Iwamoto, K., K. I. Ohshima, and T. Tamura, 2014: Improved mapping of sea ice production in the Arctic Ocean using AMSR-E thin ice thickness algorithm. J. Geophys. Res. Oceans, 119, 3574-3594, https://doi.org/10.1002/2013JC009749.

Kwok, R., 2005: Variability of Nares Strait ice flux. Geophys. Res. Lett., 32, L24502, https://doi.org/10.1029/2005GL024768.

_ - L. Toudal Pedersen, P. Gudmandsen, and S. S. Pang, 2010: Large sea ice outflow into the Nares Strait in 2007. Geophys. Res. Lett., 37, L03502, https://doi.org/10.1029/ 2009GL041872.

Mayr, G. J., and Coauthors, 2007: Gap flows: Results from the Mesoscale Alpine Programme. Quart. J. Roy. Meteor. Soc., 133, 881-896, https://doi.org/10.1002/qj.66.

Melling, H., 2011: The best laid schemes: A Nares Strait adventure. Oceanography, 24 (3), 124-125, https://doi.org/ 10.5670/oceanog.2011.63.

Moore, G. W. K., and K. Våge, 2018: Impact of model resolution on the representation on the air-sea interaction associated with the North Water polynya. Quart. J. Roy. Meteor. Soc., https:// doi.org/10.1002/qj.3295, in press.

Münchow, A., H. Melling, and K. K. Falkner, 2006: An observational estimate of volume and freshwater flux leaving the Arctic Ocean through Nares Strait. J. Phys. Oceanogr., 36, 2025-2041, https://doi.org/10.1175/JPO2962.1.

Overland, J. E., 1984: Scale analysis of marine winds in straits and along mountainous coasts. Mon. Wea. Rev., 112, 2530-2534, https://doi.org/10.1175/1520-0493(1984)112<2530: SAOMWI $>2.0 . \mathrm{CO} ; 2$.

Preußer, A., G. Heinemann, S. Willmes, and S. Paul, 2015: Multi-decadal variability of polynya characteristics and ice production in the North Water polynya by means of passive microwave and thermal infrared satellite imagery. Remote Sens., 7, 15 844-15 867, https://doi.org/10.3390/ rs71215807.

,,$-- \ldots$, and ——, 2016: Circumpolar polynya regions and ice production in the Arctic: Results from MODIS thermal infrared imagery for 2002/2003 to 2014/2015 with a regional focus on the Laptev Sea. Cryosphere, 10, 3021-3042, https:// doi.org/10.5194/tc-10-3021-2016. 
Samelson, R. M., and P. L. Barbour, 2008: Low-level jets, orographic effects, and extreme events in Nares Strait: A modelbased mesoscale climatology. Mon. Wea. Rev., 136, 4746-4759, https://doi.org/10.1175/2007MWR2326.1.

—_, T. Agnew, H. Melling, and A. Münchow, 2006: Evidence for atmospheric control of sea-ice motion through Nares Strait. Geophys. Res. Lett., 33, L02506, https://doi.org/10.1029/ 2005 GL025016.

Sharp, J., and C. F. Mass, 2004: Columbia Gorge gap winds: Their climatological influence and synoptic evolution. Wea. Forecasting, 19, 970-992, https://doi.org/10.1175/ 826.1 .
Steffen, K., 1985: Warm water cells in the North Water, northern Baffin Bay during winter. J. Geophys. Res., 90, 9129-9136, https://doi.org/10.1029/JC090iC05p09129.

USGS/NGA, 2010: Global Multi-Resolution Terrain Elevation Data 2010 (GMTED2010). U.S. Geological Survey, accessed 14 May 2018, https://lta.cr.usgs.gov/GMTED2010.

Wesche, C., D. Steinhage, and U. Nixdorf, 2016: Polar aircraft Polar5 and Polar6 operated by the Alfred Wegener Institute. J. LargeScale Res. Facil., 2, A87, https://doi.org/10.17815/jlsrf-2-153.

Yao, T., and C. L. Tang, 2003: The formation and maintenance of the North Water polynya. Atmos.-Ocean, 41, 187-201, https:// doi.org/10.3137/ao.410301. 